\title{
Overaugmentation to compensate for postextraction ridge atrophy using a putty-type porcine bone substitute material with recombinant bone morphogenetic protein-2: 4 weeks of healing in a canine model
}

\author{
Lim, Hyun-Chang ; Yoon, So-Ra ; Cha, Jae-Kook ; Lee, Jung-Seok ; Thoma, Daniel S ; Jung, Ui-Won
}

\begin{abstract}
OBJECTIVES The aims of the present study were (i) to determine the short-term effects of putty-type porcine bone substitute material (PB) with recombinant bone morphogenetic protein-2 (rhBMP-2) for alveolar ridge preservation (ARP) and (ii) evaluate the early healing of labial overaugmentation. MATERIALS AND METHODS Two groups were randomly assigned to the extraction sockets in mandibular incisors of eight dogs: labial overaugmentation with (i) PB (control) or (ii) rhBMP-2-loaded PB (BMP). Microcomputed tomography (micro-CT), and histologic and histomorphometric analyses were performed after 4 weeks. RESULTS Micro-CT revealed that some of the overaugmented PB was dispersed in both groups. The new bone volume was significantly larger in the BMP group than in the control group $(18.4 \pm 3.3$ vs. $15.5 \pm 3.0 \mathrm{~mm}$, mean $\pm \mathrm{SD}, \mathrm{P}<0.05)$. Labial bone resorption was generally found histologically. No signs of mineralization were observed in the overaugmented area despite significantly increased ridge width, as compared to the adjacent tooth area. The area of new bone formation was larger in the BMP group than in the control group overall (23.7 \pm 18.8 vs. $18.3 \pm 21.2 \mathrm{~mm})$ and in three parts (apical, middle, and coronal), although the difference was statistically significant only in the coronal part $(7.7 \pm 7.9$ vs. $4.6 \pm 6.4 \mathrm{~mm}, \mathrm{P}<0.05)$. CONCLUSIONS The addition of rhBMP-2 enhanced ossification in the coronal part of the extraction socket relative to using PB alone. Overaugmentation increased the ridge dimension with no evidence of ossification in situ at 4 weeks. CLINICAL RELEVANCE In early healing following ARP, rhBMP-2 enhances bone formation within the socket, but ossification in the overaugmented area needs to be studied further.
\end{abstract}

DOI: https://doi.org/10.1007/s00784-018-2663-Z

Posted at the Zurich Open Repository and Archive, University of Zurich

ZORA URL: https://doi.org/10.5167/uzh-158036

Journal Article

Accepted Version

Originally published at:

Lim, Hyun-Chang; Yoon, So-Ra; Cha, Jae-Kook; Lee, Jung-Seok; Thoma, Daniel S; Jung, Ui-Won (2019). Overaugmentation to compensate for postextraction ridge atrophy using a putty-type porcine bone substitute material with recombinant bone morphogenetic protein-2: 4 weeks of healing in a canine model. Clinical Oral Investigations, 23(5):2465-2474.

DOI: https://doi.org/10.1007/s00784-018-2663-z 
Overaugmentation to compensate for postextraction ridge atrophy using a putty-type porcine bone substitute material with recombinant bone morphogenetic protein-2: 4 weeks of healing in a canine model.

Hyun-Chang Lim ${ }^{1,3}$, So-Ra Yoon ${ }^{2}$, Jae-Kook Cha ${ }^{2}$,Jung-Seok Lee ${ }^{2}$, Daniel S. Thoma ${ }^{3}$, Ui-Won Jung ${ }^{2}$

\author{
Authors' affiliations: \\ ${ }^{1}$ Department of Periodontology, School of Dentistry, Kyung Hee University, Seoul, Korea \\ ${ }^{2}$ Department of Periodontology, Research Institute for Periodontal Regeneration, College of Dentistry, Yonsei \\ University, Seoul, Korea \\ ${ }^{3}$ Clinic for Fixed and Removable Prosthodontics and Dental Material Science, University of Zurich, Zurich, \\ Switzerland
}

Running title: Overaugmentation for alveolar ridge preservation

\title{
Correspondence author:
}

Ui-Won Jung, DDS, PhD

Department of Periodontology, Research Institute for Periodontal Regeneration, College of Dentistry, Yonsei University, 50-1 Yonsei-ro, Seodaemun-gu, Seoul, 03722, Republic of Korea

Tel.: $+82-2-22283185$

Fax: +82-2-3920398

E-mail:drjew@yuhs.ac 


\begin{abstract}
Objectives: (i) to determine the short-term effects of putty-type porcine bone substitute material (PB) with recombinant bone morphogenetic protein-2 (rhBMP-2) for alveolar ridge preservation (ARP) and (ii) evaluate the early healing of labial overaugmentation.
\end{abstract}

Materials and Methods: Two groups were randomly assigned to the extraction sockets in mandibular incisors of eight dogs: labial overaugmentation with (i) PB (control) or (ii) rhBMP-2-loaded PB (BMP). Microcomputed tomography (micro-CT), and histologic and histomorphometric analyses were performed after 4 weeks.

Results: Micro-CT revealed that some of the overaugmented PB was dispersed in both groups. The new bone volume was significant larger in the BMP group than control group $\left(18.4 \pm 3.3\right.$ vs. $15.5 \pm 3.0 \mathrm{~mm}^{3}$, mean $\pm \mathrm{SD}$, $P<0.05)$. Labial bone resorption was generally found histologically. No signs of mineralization were observed in the overaugmented area despite significantly increased ridge width, as compared to the adjacent tooth area. The area of new bone formation was larger in the BMP group than control group overall $(23.7 \pm 18.8$ vs. $18.3 \pm 21.2 \mathrm{~mm}^{2}$ ) and in three parts (apical, middle, and coronal), although the difference was statistically significant only in the coronal part ( $7.7 \pm 7.9$ vs. $\left.4.6 \pm 6.4 \mathrm{~mm}^{2}, P<0.05\right)$.

Conclusions: The addition of rhBMP-2 enhanced ossification in the coronal part of the extraction socket relative to using $\mathrm{PB}$ alone. Overaugmentation increased the ridge dimension with no evidence of ossification in situ at 4 weeks.

Clinical Relevance: In early healing following ARP, rhBMP-2 enhances bone formation within the socket, but ossification in the overaugmented area needs to be studied further.

Keywords: animal model, bone regeneration, ridge preservation, rhBMP-2 


\section{Introduction}

Tooth extraction leads to resorption of the tooth-supporting hard tissue, which is a natural phenomenon that might compromise implant placement in a prosthetically-driven position. Even though conventional approaches for managing bone deficiencies have been demonstrated to be predictable, they are surgically demanding and increase patient morbidity. Therefore, intervening at the time of extraction against the foreseeable results, which is called alveolar ridge preservation (ARP), has been receiving increasing attention in implant dentistry [1-5].

Various protocols and biomaterials have been investigated for ARP in a variety of clinical and preclinical settings [6]. Despite their heterogeneity, recent systematic reviews and meta-analyses have found ARP to be favorable for preventing shrinkage of the ridge width and volume. Varying amount of the weighted mean differences (WMD) between ARP-received sites and naturally healed sites have noted $[1,4,5,7,8]$, and the WMD of bone width and height were in the ranges of 1-3 $\mathrm{mm}$ and $0.7-2 \mathrm{~mm}$, respectively. Moreover, ARP reduced the frequency of additional augmentation related to implant placement (relative risk $=0.15$ ) [3], irrespective of implant feasibility $[1,3,4]$.

However, some clinical issues are still remained to be resolved. The healing periods reported for clinical studies have ranged from 3 to 12 months [2]. This meta-analysis of histomorphometric results following ARP demonstrated that the healing period led to no significant difference between ARP-received sites and naturally healed sites, and implant placement could be performed at 3-4 months post-ARP. However, considering that type 1 and 2 placements are also feasible, predominantly in anterior and premolar regions with moderate bone deficiencies, 3-4 months of healing can be considered rather long. Earlier placement of implant in ARP-received sites can be attempted, but this might result in difficulties in obtaining primary implant stability and displacement of bone substitute materials. Thus, it brings clinical advantage to find a way of advancing the timing of implant placement after ARP.

Current ARP methods may not adequately overcome an unfavorable morphology of pre-extracted alveolar bone to allow for implant placement, such as a small buccolingual dimension in the original socket or a large facial concavity [9]. Such clinical situations may require additional bone augmentation concomitantly with implant placement even in ARP-treated sites. Fickl et al. evaluated buccal overbuilding of the extraction socket and concluded that this could not reliably increase the ridge dimension $[10,11]$, indicating that ARP may be 
effective within the boundary of socket walls. However, considering the reasons for performing ARP (avoiding additional augmentation and simplifying future implant placement), overaugmentation is clinically required to compensate for postoperative changes in the ridge width and volume.

Conventional ARP methods cannot adequately address the above issues. In order to achieve the acceleration of healing as well as the overaugmented ridge following ARP, an enhancer and a specific-type bone substitute may be required. Lee et al. applied a mixture of bovine bone mineral and hydroxyapatite-coated ACS-loaded recombinant bone morphogenetic protein-2 (rhBMP-2) to extraction sockets lacking the buccal bone plate in a canine model [12]. They described that the addition of rhBMP-2 not only minimized ridge shrinkage but also enhanced new bone formation compared to grafting bovine bone mineral only. Considering this study demonstrated that rhBMP-2 is beneficial in the challenging situation, rhBMP-2 may have a potential to accelerate healing in ARP. Furthermore, putty-type bone substitute may provide structural stability and welladaptability when used for overaugmentation on the outer surface of the socket, due to its moldability.

The aims of the present study were (i) to determine the short-term effects of a putty-type porcine bone substitute material (PB) with or without the addition of rhBMP-2 for ARP and (ii) evaluate the early healing of labial overaugmentation. 


\section{Materials and methods}

This study was conducted following the 3Rs principles (Replacement, Reduction, and Refinement) for a preclinical study [13]. The manuscript was prepared following the ARRIVE (Animal Research: Reporting In Vivo Experiments) guidelines [14].

\section{Animals}

Eight male beagle dogs weighing 10-12 kg were used in this study (Gukje, Pocheon, Korea). They had a healthy systemic condition and an intact periodontium. The animals were housed individually in cages at a room temperature of $15-20^{\circ} \mathrm{C}$ and a humidity of $>30 \%$. All procedures for the animal experiments were approved by the Institutional Animal Care and Use Committee of Yonsei Medical Center, Seoul, Korea (IACUC Approval No. 2013-0317-4). The experiments were carried out during July and August 2014.

\section{Study design}

Mandibular incisors (\#303 and \#403 in the modified Triadan system) served as recipient sites. Following tooth extraction, the extraction sockets were assigned to one of the following two groups: (i) extraction socket filled and overaugmented with PB (control group) or (ii) extraction socket filled and overaugmented with Escherichia coli-derived rhBMP-2-loaded PB (0.5 mg/ml, Cowellmedi, Busan, Korea) (BMP group). Mandibular incisor sites with teeth present (\#302 and \#402) served as reference sites (no extractions or augmentation).

\section{Putty-type porcine bone}

The porcine bone powder (SK Bioland, Cheongju, Korea) was initially washed with deionized water to clear away any blood, then heated for 48 hours in deionized water before being washed again. Finally the powder was treated with $10 \% \mathrm{H}_{2} \mathrm{O}_{2}$ for 12 hours and washed with deionized water a further three times before being transferred to an oven at $80^{\circ} \mathrm{C}$ for drying. The dried powder was then sintered at $800^{\circ} \mathrm{C}$ for 4 hours. Only the cancellous part of porcine bone was used. 
Pluronic F127 powder (BASF Corporation, Ludwigshafen, Germany) was dissolved with deionized water at $4^{\circ} \mathrm{C}$ to a concentration of $35 \%$, and mixed with the bone power at a bone-to-pluronic-F127-powder volume ratio of 1:2. This mixture was then placed in an oven at $30^{\circ} \mathrm{C}$ to dry for 24 hours.

\section{Surgery}

A subcutaneous injection of atropine $(0.05 \mathrm{mg} / \mathrm{kg}$; Kwangmyung Pharmaceutical, Seoul, Korea) and an intravenous injection of xylazine (Rompun, Bayer Korea, Seoul, Korea) and Zoletil (Virbac, Carros, France) were used to induce general anesthesia. During the surgical procedure, inhalation of enflurane (Gerolan, Choongwae Pharmaceutical, Seoul, Korea) was used via tracheal intubation for maintaining the anesthetic state. Local anesthesia (2\% lidocaine $\mathrm{HCl}$, Huons, Seoul, Korea) was applied to the surgical sites. The group allocation in the first experimental animals was decided by coin flipping, and then assigned alternately for the remaining the animals.

Two vertical incisions were made in the mesial and distal areas of the mandibular lateral incisors, and the incisors were carefully extracted using forceps. No labiolingual force was applied so as to avoid traumatic injury of the labial bone. Following extraction: either PB only (control) or rhBMP-2-loaded PB (BMP). For the BMP group, PB was soaked in $0.1 \mathrm{ml}$ of rhBMP-2 at a concentration of $0.5 \mathrm{mg} / \mathrm{ml}$ for 10 minutes, and then gently pushed into the extraction socket with a plugger and laid on the labial bone at an approximate thickness of $2 \mathrm{~mm}$ (Fig. 1). No barrier membrane was used. The labial flap was released by a periosteal releasing incision to achieve a tension-free flap closure. Flaps were sutured with 6-0 nylon (Monosyn, Aesculap, B-Braun, Center Valley, PA, USA). Antibiotic $(20 \mathrm{mg} / \mathrm{kg}$; cefazolin, Yuhan, Seoul, South Korea) was administered intramuscularly for 3 days postoperatively, with the wounds disinfected using chlorhexidine on a daily basis. The animals were provided with a soft diet for the entire healing period. After 4 weeks of healing, the dogs were sacrificed by an overdose of pentobarbital sodium $(90-120 \mathrm{mg} / \mathrm{kg})$.

\section{Microcomputed tomography (micro-CT) analysis}

Block sections of the experimental sites were harvested and immersed in 5\% formic acid for 14 days. Micro- 
CT scanning was performed (SkyScan 1072, SkyScan, Aartselaar, Belgium) at a resolution of $35 \mu \mathrm{m}$ (achieved using $100 \mathrm{kV}$ and $100 \mu \mathrm{A}$ ). The acquired data were reconstructed with NRecon software (version 1.6.8.0, SkyScan).

\section{Linear measurements}

Two assumptions were made for the linear measurements: (i) the lingual bone plate was considered to undergo minimal resorption and (ii) the alveolus of the adjacent central incisors had similar dimensions to the recipient sites. Vertical reference lines were drawn along the long axis in the center of the recipient sockets and tooth sites (central incisors). Lines were drawn perpendicular to each vertical reference at 1, 3, and $5 \mathrm{~mm}$ below the lingual crest, where the horizontal width was measured: $\mathrm{HW}_{1}, \mathrm{HW}_{3}$, and $\mathrm{HW}_{5}$.

\section{Volumetric measurements}

The grayscale threshold values for PB and new bone were standardized. The corresponding values were within the ranges of 115-225 and 69-115, respectively. The following parameters were measured:

- $\quad \mathrm{TV}\left(\mathrm{mm}^{3}\right)$ : volume of total augmented area (alveolus plus overaugmented area).

- $\quad \mathrm{NV}\left(\mathrm{mm}^{3}\right)$ : volume of newly formed bone.

- $\quad \mathrm{RV}\left(\mathrm{mm}^{3}\right)$ : volume of residual PB.

\section{Histologic processing and histomorphometric analysis}

The resected specimens were decalcified, trimmed, and embedded in paraffin. The blocks were sectioned serially at $5 \mu \mathrm{m}$ perpendicularly to the long axis of the socket. The central-most section was chosen for histologic and histomorphometric analyses. Hematoxylin/eosin and Masson's trichrome staining were performed. The histologic slides were observed with the aid of a light microscope (BX51, Olympus Research Systems, Tokyo, Japan). The histomorphometric analysis was performed using image analysis software (Photoshop CS6, Adobe, California, USA) by single experienced investigator (H.C.L.). The group assignment was not revealed during the analysis.

The histomorphometric measurements were performed for both the entire augmentation (alveolus plus overaugmented area) and four parts (apical, middle and coronal 1/3in the socket and the overaugmented area) 
within the augmentation. The following parameters were assessed (Fig. 2):

- $\quad \mathrm{TA}\left(\mathrm{mm}^{2}\right)$ : total tissue area encompassing new bone, residual PB, and nonmineralized tissue.

- $\quad \mathrm{NB}\left(\mathrm{mm}^{2}\right)$ : area of newly formed bone.

- $\quad \mathrm{RM}\left(\mathrm{mm}^{2}\right)$ : area of residual PB.

- $\quad \mathrm{NM}\left(\mathrm{mm}^{2}\right)$ : area of nonmineralized tissue.

- $\quad \% \mathrm{NB}, \% \mathrm{RM}$, and $\% \mathrm{NM}$ : percentage of each value relative to TA.

\section{Statistics}

Sample size was not calculated due to the pilot nature of the present study.

Statistical analyses were performed using a commercially available statistical package (SPSS 21.0, SPSS, Chicago, IL, USA). Data are presented as mean \pm SD values. Shapiro-Wilk tests were used to check that the data conformed to a normal distribution. The paired $t$-test was used to detect significant differences in the volumetric and linear parameters obtained from micro-CT. The Wilcoxon signed-ranked test was applied to histomorphometric parameters. The cutoff for statistical significance was set at $P<0.05$. 


\section{Results}

\section{Clinical findings}

The clinical healing was uneventful in all of the experimental animals. No postoperative complications such as pus discharge or swelling were found during the healing period.

\section{Micro-CT analysis}

The grafted PB was packed within the socket and blended with newly formed mineralized bone tissue. Some of the initially overaugmented PB was dispersed in most of the specimens (Fig. 3).

The horizontal ridge widths at the three levels $\left(\mathrm{HW}_{1}, \mathrm{HW}_{3}\right.$, and $\left.\mathrm{HW}_{5}\right)$ were $7.70 \pm 0.67,9.09 \pm 0.62$, and $10.14 \pm 0.76 \mathrm{~mm}$, respectively, in the control group, and $6.40 \pm 0.49,7.19 \pm 0.50$, and $8.34 \pm 0.40 \mathrm{~mm}$ in the BMP group. There were no significant differences between the two groups $(P>0.05)$. Compared to the corresponding tooth sites, both groups showed significantly larger horizontal widths at all levels $(P<0.05)$ (Table 1$)$.

In terms of volumetric measurements, TV did not differ significantly between the control and BMP groups $\left(40.30 \pm 15.37\right.$ vs. $\left.45.99 \pm 11.36 \mathrm{~mm}^{3}, P=0.20\right)$, nor did RV (11.54 \pm 7.01 vs. $\left.12.79 \pm 6.13 \mathrm{~mm}^{3}, P=0.52\right)$. However, $\mathrm{NV}$ was significantly higher in the BMP group $\left(18.38 \pm 3.34 \mathrm{~mm}^{3}\right)$ than in the control group $\left(15.47 \pm 3.00 \mathrm{~mm}^{3}\right)$ $(P=0.047)$ (Table 2).

\section{Histologic observations}

Histologic sections from experimental dog No. 8 were excluded due to a processing error, and so histologic sections from seven animals were analyzed.

Various degrees of labial bone plate resorption were observed in both groups. In the coronal $1 / 3$, the labial plate was not maintained in most of the specimens. In addition, two specimens (one in each group) showed resorption up to the middle $1 / 3$ of the labial plate. The space originally maintained by the labial plate was replaced with fibrous tissue. This resulted in a gap in the soft tissue between the overaugmented area and the PB 
inside the alveolus. Moreover, dispersion and displacement of labially-overaugmented PB particles were observed, but there was no soft tissue fenestration or inflammatory change. Most of the initially overaugmented area was maintained in one specimen in the BMP group and three specimens in the control group (Fig. 4, 5).

Newly formed bone was mostly observed close to the socket walls. The amount of new bone appeared to be greater in the apical $1 / 3$ and adjacent to the lingual wall in both groups. New bone formation in the coronal $1 / 3$ was generally limited, with loss of PB particles and soft-tissue ingrowth being observed. Newly formed bone was partially in contact with PB particles and was evident in the intergranular spaces. Blood vessels of various sizes were observed in the socket. The number of blood vessels seemed to be higher in the apical $1 / 3$ than in the other parts. There were no signs of mineralization in the labial overaugmented area, but a few blood vessels were observed. The PB particles in the overaugmented area were surrounded by nonmineralized tissue (Figs. 4, $5)$.

\section{Histomorphometric analysis}

In the entire augmentation, no statistically significant differences were observed between the control and BMP groups for all parameters expressed as absolute values: $111.3 \pm 25.9$ vs. $117.7 \pm 30.7 \mathrm{~mm}^{2}$ for TA, $18.3 \pm 21.2$ vs. $23.7 \pm 18.8 \mathrm{~mm}^{2}$ for $\mathrm{NB}, 23.4 \pm 18.8$ vs. $23.7 \pm 12.6 \mathrm{~mm}^{2}$ for $\mathrm{RM}$, and $69.5 \pm 12.4$ vs. $70.3 \pm 18.9 \mathrm{~mm}^{2}$ for $\mathrm{NM}$ (all $P>0.05)$. There was also no significant difference between the control and BMP groups in \%NB (14.8 \pm 16.6 vs. $19.2 \pm 11.4 \%, P>0.05)$ or $\% \mathrm{NM}(64.3 \pm 15.2$ vs. $59.2 \pm 5.2 \%, P>0.05)$. However, $\%$ RM was significantly lower in the control group than in the BMP group ( $21.0 \pm 16.8 \%$ vs. $21.2 \pm 10.6 \%, P=0.018)$ (Table 3, Fig. 6 ).

Within the four parts of the augmentation there were no significant differences between the control and BMP groups in TA and NM ( $P>0.05$ for both absolute and relative values). NB in the apical, middle, and coronal 1/3 was higher in the BMP group than in the control group, but the difference was significant only in the coronal $1 / 3$ ( $7.7 \pm 7.9$ vs. $4.6 \pm 6.4 \mathrm{~mm}^{2}, 16.2 \pm 14.4 \%$ vs. $9.4 \pm 13.4 \%, P=0.018$ for both absolute and relative values for coronal 1/3). Newly formed bone was not detected in the overaugmented area in both groups. RM did not differ significantly in the apical $1 / 3$, middle $1 / 3$, or overaugmented area, but in the coronal $1 / 3$ it was significantly higher in the BMP group than in the control group (Table 3, Fig. 6). 


\section{Discussion}

The present study investigated the effect of (i) rhBMP-2-loaded PB for ARP and (ii) overaugmentation of the labial plate within a short healing period. After 4 weeks of healing the volume of new bone was significantly larger in the BMP group than in the control group. The area of new bone only in the coronal $1 / 3$ of the socket was significantly larger in the BMP group than in the control group. Some of the overaugmented PB on the labial surface tended to disperse and did not show signs of new bone formation irrespective of the addition of rhBMP-2.

Most clinical studies of ARP have demonstrated outcomes for nonmolar extraction sites with minor bone destruction within 4-6 months of healing $[1-3,7]$. The reported outcomes have included minimized ridge resorption and decreased probability of bone augmentation at the time of implant placement at ARP sites compared to naturally healed sites. However, immediate or early implant placement might also be feasible for such sites [3], and the predictability of immediate or early placement has been well-demonstrated [15]. It can therefore be argued that ARP generally delays the timing of implant placement. One method for solving this conflict may be to introduce tissue engineering technology. Previous studies using rhBMP-2 for ARP have demonstrated its feasibility and safety [16-18], but it has yet to be revealed whether rhBMP-2 can advance the timing of implant placement. In the present study, both the new bone volume as assessed using micro-CT and the new bone area assessed histologically were increased in the BMP group after 4 weeks of healing. This indicates that rhBMP-2 is a potential option for accelerating the healing for ARP.

However, it should be noted that cortical bone formation was not achieved in any of the present specimens at the most coronal aspect of the former extraction site. The presence of cortical bone in the coronal area of the ridge is crucial for primary stability. Even though the amount of new bone in the coronal $1 / 3$ of the socket increased more than twofold more in the BMP group than in the control group, the socket entrance and the outermost part of the coronal $1 / 3$ exhibited limited bone formation and some soft-tissue infiltration. From a clinical point of view, such healing requires undersized drilling to ensure primary stability or a more lingual position of the implant, or an additional bone augmentation after a partial removal of non-mineralized bone.

The aims of ARP include (i) to allow for dental implant placement and (ii) to achieve a sufficient bone-toimplant contact. This is even more critical in cases of early implant placement, since no mature bone can be 
expected to be present within the socket at such an early time point. The recent preclinical study by Thoma et al. has yielded some points to be considered regarding this issue [19]. Those authors established three experimental groups: early implant placement following ARP (after 4 weeks) with/without the removal of grafted PB and granulation tissue, and early implant placement with guided bone regeneration. They demonstrated that the bone-to-implant contact in all groups increased with time and found no relevant intergroup differences in any of the parameters. These outcomes indicated that implant placement at an early healing period following ARP is feasible without the removal of immature tissues. However, that study also indicated that a certain loss of the ridge width still has to be expected, which means that overaugmentation with ARP may be practically required in certain cases.

Almost all previous studies have indicated that ARP cannot completely prevent ridge resorption $[1,5,7]$. Moreover, the predominant procedure applied for ARP (i.e., socket filling) confines the influence of ARP within the original socket dimensions. Therefore, in cases of alveoli that are narrow and/or have unfavorable morphology, overaugmentation is practically required to avoid further augmentation at the time of implant placement [9]. Fickl et al. utilized the concept of guided bone regeneration to augment the buccal bone plate, but they found a large reduction in overaugmentation and no significant difference in the ridge dimension compared to the control group [11]. This contrasts with the present study finding significantly larger dimensions compared to the adjacent tooth sites despite some dispersion and dislocation of the augmented PB. However, irrespective of the addition of rhBMP-2, labial bone resorption led to soft-tissue infiltration into the space where the labial bone plate existed, and a layer of soft tissue formed between the overaugmented area and the alveolus. Moreover, in the overaugmented area, the PB particles were embedded with soft tissue and there was no sign of mineralized tissue formation in either group. These findings might indicate the separation between the overaugmented part and the intrasocket part, and/or subsequent fibrosis of the overaugmented part after a completion of the healing. Clinically, such might lead to a potential removal of overaugmented part and an additional bone augmentation at the time of the implant placement. However, it should be considered that the healing period used in the present study might have been too short to detect bone formation following labial overaugmentation in conjunction with ARP, and therefore further studies over a longer healing period are required.

Current ARP procedures are generally based on the concept of guided bone regeneration. Irrespective of open 
healing or primary wound closure, a barrier membrane is most often used in ARP to cover bone substitute material grafted in the socket [1]. A previous clinical trial investigated the effect of using a collagen membrane, and found that new bone formation was greater at membrane-covered sites than at non-covered sites [20]. The present study did not use a barrier membrane, which may have limit the effectiveness of the ARP procedures [21]. However, a particularly interesting finding was that, in the experimentally damaged socket, bone substitute in combination with rhBMP-2 (no membrane) resulted in comparable effects in terms of new bone formation and horizontal ridge reduction [12]. Moreover, it was suggested that the presence of a barrier membrane may hamper the action of rhBMP-2 by blocking an access of osteoprogenitor cells [22]. The use of a barrier membrane may help minimizing soft-tissue infiltration in the socket entrance and improve labial overaugmentation, but further studies are required for the simultaneous use of a barrier membrane and rhBMP-2.

The universal model used to investigate ARP procedures has been the canine mandibular premolar model [1012, 23-26]. The ARP procedure in that model includes hemisectioning the premolars and performing root canal filling to the residual roots $[10,11]$. Extracting the premolars in toto will increase the number of experimental sites available. However, this results in pronounced ridge resorption due to performing multiple continuous extractions [27]. The present model using mandibular incisors appears to be a valid alternative to the premolar model due to simplicity of the procedure (no hemisectioning or root canal filling). Moreover, the orofacial width of the incisor in the present model was approximately $4.5 \mathrm{~mm}$, which corresponds to that of the premolars in canines (width ranging from 3.8 to $4.3 \mathrm{~mm}$ ) [23, 24, 28]. 


\section{Conclusions}

The addition of rhBMP-2 enhanced ossification in the coronal part of the extraction socket in ARP relative to using PB alone at 4 weeks of healing. Overaugmentation of the labial surface of the alveolus increased the dimensions of the socket despite some dispersion of the PB. However, clinical benefit should be further studied in a longer follow-up. 


\section{Acknowledgement}

\section{Compliance with ethical standards}

\section{Conflicts of interest}

The authors declare that they have no conflicts of interest.

\section{Funding}

This work was supported by the National Research Foundation of Korea (NRF) grant funded by the Korea government (Ministry of Science, ICT \& Future Planning) (No. NRF-2017R1A2B2002537).

\section{Ethical approval}

This article does not contain any studies with human participants performed by any of the authors. All applicable international, national, and/or institutional guidelines for the care and use of animals were followed Informed consent

The present study does not require informed consent. 


\section{References}

[1] Avila-Ortiz G, Elangovan S, Kramer KW, Blanchette D and Dawson DV (2014) Effect of alveolar ridge preservation after tooth extraction: a systematic review and meta-analysis. Journal of dental research 93:950-8. doi: $10.1177 / 0022034514541127$

[2] De Risi V, Clementini M, Vittorini G, Mannocci A and De Sanctis M (2015) Alveolar ridge preservation techniques: a systematic review and meta-analysis of histological and histomorphometrical data. Clinical oral implants research 26:50-68. doi: 10.1111/clr.12288

[3] Mardas N, Trullenque-Eriksson A, MacBeth N, Petrie A and Donos N (2015) Does ridge preservation following tooth extraction improve implant treatment outcomes: a systematic review: Group 4: Therapeutic concepts \& methods. Clinical oral implants research 26 Suppl 11:180-201. doi: 10.1111/clr.12639

[4] Vignoletti F, Matesanz P, Rodrigo D, Figuero E, Martin C and Sanz M (2012) Surgical protocols for ridge preservation after tooth extraction. A systematic review. Clinical oral implants research 23 Suppl 5:22-38. doi: 10.1111/j.1600-0501.2011.02331.x

[5] Willenbacher M, Al-Nawas B, Berres M, Kammerer PW and Schiegnitz E (2015) The Effects of Alveolar Ridge Preservation: A Meta-Analysis. Clinical implant dentistry and related research. doi: 10.1111/cid.12364

[6] Wang RE and Lang NP (2012) Ridge preservation after tooth extraction. Clinical oral implants research 23 Suppl 6:147-56. doi: 10.1111/j.1600-0501.2012.02560.x

[7] MacBeth N, Trullenque-Eriksson A, Donos N and Mardas N (2016) Hard and soft tissue changes following alveolar ridge preservation: a systematic review. Clinical oral implants research. doi: 10.1111/clr.12911

[8] Vittorini Orgeas G, Clementini M, De Risi V and de Sanctis M (2013) Surgical techniques for alveolar socket preservation: a systematic review. The International journal of oral \& maxillofacial implants 28:1049-61. doi: $10.11607 /$ jomi.2670

[9] Iasella JM, Greenwell H, Miller RL, Hill M, Drisko C, Bohra AA and Scheetz JP (2003) Ridge preservation with freeze-dried bone allograft and a collagen membrane compared to extraction alone for implant site development: a clinical and histologic study in humans. Journal of periodontology 74:990-9. doi: 10.1902/jop.2003.74.7.990

[10] Fickl S, Schneider D, Zuhr O, Hinze M, Ender A, Jung RE and Hurzeler MB (2009) Dimensional changes of the ridge contour after socket preservation and buccal overbuilding: an animal study. Journal of clinical periodontology 36:442-8. doi: 10.1111/j.1600-051X.2009.01381.x 
[11] Fickl S, Zuhr O, Wachtel H, Kebschull M and Hurzeler MB (2009) Hard tissue alterations after socket preservation with additional buccal overbuilding: a study in the beagle dog. Journal of clinical periodontology 36:898-904. doi: 10.1111/j.1600-051X.2009.01463.x

[12] Lee JS, Jung JS, Im GI, Kim BS, Cho KS and Kim CS (2015) Ridge regeneration of damaged extraction sockets using rhBMP-2: an experimental study in canine. Journal of clinical periodontology 42:678-87. doi: $10.1111 /$ jcpe. 12414

[13] Vignoletti F and Abrahamsson I (2012) Quality of reporting of experimental research in implant dentistry. Critical aspects in design, outcome assessment and model validation. Journal of clinical periodontology 39 Suppl 12:6-27. doi: 10.1111/j.1600-051X.2011.01830.x

[14] Kilkenny C, Browne WJ, Cuthill IC, Emerson M and Altman DG (2010) Improving bioscience research reporting: the ARRIVE guidelines for reporting animal research. PLoS Biol 8:e1000412. doi: 10.1371/journal.pbio. 1000412

[15] Sanz-Sanchez I, Ortiz-Vigon A, Sanz-Martin I, Figuero E and Sanz M (2015) Effectiveness of Lateral Bone Augmentation on the Alveolar Crest Dimension: A Systematic Review and Meta-analysis. Journal of dental research 94:128S-42S. doi: 10.1177/0022034515594780

[16] Fiorellini JP, Howell TH, Cochran D, Malmquist J, Lilly LC, Spagnoli D, Toljanic J, Jones A and Nevins M (2005) Randomized study evaluating recombinant human bone morphogenetic protein-2 for extraction socket augmentation. Journal of periodontology 76:605-13. doi: 10.1902/jop.2005.76.4.605

[17] Howell TH, Fiorellini J, Jones A, Alder M, Nummikoski P, Lazaro M, Lilly L and Cochran D (1997) A feasibility study evaluating rhBMP-2/absorbable collagen sponge device for local alveolar ridge preservation or augmentation. The International journal of periodontics \& restorative dentistry 17:124-39.

[18] Kim YJ, Lee JY, Kim JE, Park JC, Shin SW and Cho KS (2014) Ridge preservation using demineralized bone matrix gel with recombinant human bone morphogenetic protein-2 after tooth extraction: a randomized controlled clinical trial. Journal of oral and maxillofacial surgery : official journal of the American Association of Oral and Maxillofacial Surgeons 72:1281-90. doi: 10.1016/j.joms.2014.01.022

[19] Thoma DS, Naenni N, Benic GI, Munoz F, Hammerle CHF and Jung RE (2017) Effect of ridge preservation for early implant placement - is there a need to remove the biomaterial? Journal of clinical periodontology 44:556-565. doi: 10.1111/jcpe.12709

[20] Perelman-Karmon M, Kozlovsky A, Liloy R and Artzi Z (2012) Socket site preservation using bovine bone 
mineral with and without a bioresorbable collagen membrane. The International journal of periodontics \& restorative dentistry 32:459-65.

[21] Jung UW, Lee JS, Lee G, Lee IK, Hwang JW, Kim MS, Choi SH and Chai JK (2013) Role of collagen membrane in lateral onlay grafting with bovine hydroxyapatite incorporated with collagen matrix in dogs. $\mathbf{J}$ Periodontal Implant Sci 43:64-71. doi: 10.5051/jpis.2013.43.2.64

[22] Cochran DL, Schenk R, Buser D, Wozney JM and Jones AA (1999) Recombinant human bone morphogenetic protein-2 stimulation of bone formation around endosseous dental implants. Journal of periodontology 70:139-50. doi: 10.1902/jop.1999.70.2.139

[23] Araujo MG, Wennstrom JL and Lindhe J (2006) Modeling of the buccal and lingual bone walls of fresh extraction sites following implant installation. Clinical oral implants research 17:606-14. doi: 10.1111/j.16000501.2006.01315.x

[24] Caneva M, Botticelli D, Pantani F, Baffone GM, Rangel IG, Jr. and Lang NP (2012) Deproteinized bovine bone mineral in marginal defects at implants installed immediately into extraction sockets: an experimental study in dogs. Clinical oral implants research 23:106-12. doi: 10.1111/j.1600-0501.2011.02202.x

[25] Delgado-Ruiz R, Romanos GE, Alexandre Gerhke S, Gomez-Moreno G, Mate-Sanchez de Val JE and Calvo-Guirado JL (2016) Biological effects of compressive forces exerted on particulate bone grafts during socket preservation: animal study. Clinical oral implants research. doi: 10.1111/clr.12942

[26] Kim JJ, Schwarz F, Song HY, Choi Y, Kang KR and Koo KT (2016) Ridge preservation of extraction sockets with chronic pathology using Bio-Oss(R) Collagen with or without collagen membrane: an experimental study in dogs. Clinical oral implants research. doi: 10.1111/clr.12870

[27] Al-Askar M, O'Neill R, Stark PC, Griffin T, Javed F and Al-Hezaimi K (2013) Effect of single and contiguous teeth extractions on alveolar bone remodeling: a study in dogs. Clinical implant dentistry and related research 15:569-75. doi: 10.1111/j.1708-8208.2011.00403.x

[28] Calvo-Guirado JL, Boquete-Castro A, Negri B, Delgado Ruiz R, Gomez-Moreno G and Iezzi G (2014) Crestal bone reactions to immediate implants placed at different levels in relation to crestal bone. A pilot study in Foxhound dogs. Clinical oral implants research 25:344-51. doi: 10.1111/clr.12110

[1] Avila-Ortiz G, Elangovan S, Kramer KW, Blanchette D and Dawson DV (2014) Effect of alveolar ridge preservation after tooth extraction: a systematic review and meta-analysis. Journal of dental research 93:950-8. doi: $10.1177 / 0022034514541127$ 
[2] De Risi V, Clementini M, Vittorini G, Mannocci A and De Sanctis M (2015) Alveolar ridge preservation techniques: a systematic review and meta-analysis of histological and histomorphometrical data. Clinical oral implants research 26:50-68. doi: 10.1111/clr.12288

[3] Mardas N, Trullenque-Eriksson A, MacBeth N, Petrie A and Donos N (2015) Does ridge preservation following tooth extraction improve implant treatment outcomes: a systematic review: Group 4: Therapeutic concepts \& methods. Clinical oral implants research 26 Suppl 11:180-201. doi: 10.1111/clr.12639

[4] Vignoletti F, Matesanz P, Rodrigo D, Figuero E, Martin C and Sanz M (2012) Surgical protocols for ridge preservation after tooth extraction. A systematic review. Clinical oral implants research 23 Suppl 5:22-38. doi: 10.1111/j.1600-0501.2011.02331.x

[5] Willenbacher M, Al-Nawas B, Berres M, Kammerer PW and Schiegnitz E (2015) The Effects of Alveolar Ridge Preservation: A Meta-Analysis. Clinical implant dentistry and related research. doi: 10.1111/cid.12364

[6] Wang RE and Lang NP (2012) Ridge preservation after tooth extraction. Clinical oral implants research 23 Suppl 6:147-56. doi: 10.1111/j.1600-0501.2012.02560.x

[7] MacBeth N, Trullenque-Eriksson A, Donos N and Mardas N (2016) Hard and soft tissue changes following alveolar ridge preservation: a systematic review. Clinical oral implants research. doi: 10.1111/clr.12911

[8] Vittorini Orgeas G, Clementini M, De Risi V and de Sanctis M (2013) Surgical techniques for alveolar socket preservation: a systematic review. The International journal of oral \& maxillofacial implants 28:1049-61. doi: $10.11607 /$ jomi.2670

[9] Iasella JM, Greenwell H, Miller RL, Hill M, Drisko C, Bohra AA and Scheetz JP (2003) Ridge preservation with freeze-dried bone allograft and a collagen membrane compared to extraction alone for implant site development: a clinical and histologic study in humans. Journal of periodontology 74:990-9. doi: 10.1902/jop.2003.74.7.990

[10] Fickl S, Schneider D, Zuhr O, Hinze M, Ender A, Jung RE and Hurzeler MB (2009) Dimensional changes of the ridge contour after socket preservation and buccal overbuilding: an animal study. Journal of clinical periodontology 36:442-8. doi: 10.1111/j.1600-051X.2009.01381.x

[11] Fickl S, Zuhr O, Wachtel H, Kebschull M and Hurzeler MB (2009) Hard tissue alterations after socket preservation with additional buccal overbuilding: a study in the beagle dog. Journal of clinical periodontology 36:898-904. doi: 10.1111/j.1600-051X.2009.01463.x

[12] Lee JS, Jung JS, Im GI, Kim BS, Cho KS and Kim CS (2015) Ridge regeneration of damaged extraction 
sockets using rhBMP-2: an experimental study in canine. Journal of clinical periodontology 42:678-87. doi: $10.1111 /$ jcpe. 12414

[13] Vignoletti F and Abrahamsson I (2012) Quality of reporting of experimental research in implant dentistry. Critical aspects in design, outcome assessment and model validation. Journal of clinical periodontology 39 Suppl 12:6-27. doi: 10.1111/j.1600-051X.2011.01830.x

[14] Kilkenny C, Browne WJ, Cuthill IC, Emerson M and Altman DG (2010) Improving bioscience research reporting: the ARRIVE guidelines for reporting animal research. PLoS Biol 8:e1000412. doi: 10.1371/journal.pbio. 1000412

[15] Sanz-Sanchez I, Ortiz-Vigon A, Sanz-Martin I, Figuero E and Sanz M (2015) Effectiveness of Lateral Bone Augmentation on the Alveolar Crest Dimension: A Systematic Review and Meta-analysis. Journal of dental research 94:128S-42S. doi: 10.1177/0022034515594780

[16] Fiorellini JP, Howell TH, Cochran D, Malmquist J, Lilly LC, Spagnoli D, Toljanic J, Jones A and Nevins M (2005) Randomized study evaluating recombinant human bone morphogenetic protein-2 for extraction socket augmentation. Journal of periodontology 76:605-13. doi: 10.1902/jop.2005.76.4.605

[17] Howell TH, Fiorellini J, Jones A, Alder M, Nummikoski P, Lazaro M, Lilly L and Cochran D (1997) A feasibility study evaluating rhBMP-2/absorbable collagen sponge device for local alveolar ridge preservation or augmentation. The International journal of periodontics \& restorative dentistry 17:124-39.

[18] Kim YJ, Lee JY, Kim JE, Park JC, Shin SW and Cho KS (2014) Ridge preservation using demineralized bone matrix gel with recombinant human bone morphogenetic protein-2 after tooth extraction: a randomized controlled clinical trial. Journal of oral and maxillofacial surgery : official journal of the American Association of Oral and Maxillofacial Surgeons 72:1281-90. doi: 10.1016/j.joms.2014.01.022

[19] Thoma DS, Naenni N, Benic GI, Munoz F, Hammerle CHF and Jung RE (2017) Effect of ridge preservation for early implant placement - is there a need to remove the biomaterial? Journal of clinical periodontology 44:556-565. doi: 10.1111/jcpe. 12709

[20] Perelman-Karmon M, Kozlovsky A, Liloy R and Artzi Z (2012) Socket site preservation using bovine bone mineral with and without a bioresorbable collagen membrane. The International journal of periodontics \& restorative dentistry 32:459-65.

[21] Jung UW, Lee JS, Lee G, Lee IK, Hwang JW, Kim MS, Choi SH and Chai JK (2013) Role of collagen membrane in lateral onlay grafting with bovine hydroxyapatite incorporated with collagen matrix in dogs. $\mathrm{J}$ 
Periodontal Implant Sci 43:64-71. doi: 10.5051/jpis.2013.43.2.64

[22] Araujo MG, Wennstrom JL and Lindhe J (2006) Modeling of the buccal and lingual bone walls of fresh extraction sites following implant installation. Clinical oral implants research 17:606-14. doi: 10.1111/j.16000501.2006.01315.x

[23] Caneva M, Botticelli D, Pantani F, Baffone GM, Rangel IG, Jr. and Lang NP (2012) Deproteinized bovine bone mineral in marginal defects at implants installed immediately into extraction sockets: an experimental study in dogs. Clinical oral implants research 23:106-12. doi: 10.1111/j.1600-0501.2011.02202.x

[24] Delgado-Ruiz R, Romanos GE, Alexandre Gerhke S, Gomez-Moreno G, Mate-Sanchez de Val JE and Calvo-Guirado JL (2016) Biological effects of compressive forces exerted on particulate bone grafts during socket preservation: animal study. Clinical oral implants research. doi: 10.1111/clr.12942

[25] Kim JJ, Schwarz F, Song HY, Choi Y, Kang KR and Koo KT (2016) Ridge preservation of extraction sockets with chronic pathology using Bio-Oss(R) Collagen with or without collagen membrane: an experimental study in dogs. Clinical oral implants research. doi: 10.1111/clr.12870

[26] Al-Askar M, O'Neill R, Stark PC, Griffin T, Javed F and Al-Hezaimi K (2013) Effect of single and contiguous teeth extractions on alveolar bone remodeling: a study in dogs. Clinical implant dentistry and related research 15:569-75. doi: 10.1111/j.1708-8208.2011.00403.x

[27] Calvo-Guirado JL, Boquete-Castro A, Negri B, Delgado Ruiz R, Gomez-Moreno G and Iezzi G (2014) Crestal bone reactions to immediate implants placed at different levels in relation to crestal bone. A pilot study in Foxhound dogs. Clinical oral implants research 25:344-51. doi: 10.1111/clr.12110

[1] Avila-Ortiz G, Elangovan S, Kramer KW, Blanchette D and Dawson DV (2014) Effect of alveolar ridge preservation after tooth extraction: a systematic review and meta-analysis. Journal of dental research 93:950-8. doi: $10.1177 / 0022034514541127$

[2] De Risi V, Clementini M, Vittorini G, Mannocci A and De Sanctis M (2015) Alveolar ridge preservation techniques: a systematic review and meta-analysis of histological and histomorphometrical data. Clinical oral implants research 26:50-68. doi: 10.1111/clr.12288

[3] Mardas N, Trullenque-Eriksson A, MacBeth N, Petrie A and Donos N (2015) Does ridge preservation following tooth extraction improve implant treatment outcomes: a systematic review: Group 4: Therapeutic concepts \& methods. Clinical oral implants research 26 Suppl 11:180-201. doi: 10.1111/clr.12639

[4] Vignoletti F, Matesanz P, Rodrigo D, Figuero E, Martin C and Sanz M (2012) Surgical protocols for ridge 
preservation after tooth extraction. A systematic review. Clinical oral implants research 23 Suppl 5:22-38. doi: $10.1111 / \mathrm{j} .1600-0501.2011 .02331 . \mathrm{x}$

[5] Willenbacher M, Al-Nawas B, Berres M, Kammerer PW and Schiegnitz E (2015) The Effects of Alveolar Ridge Preservation: A Meta-Analysis. Clinical implant dentistry and related research. doi: 10.1111/cid.12364 [6] Wang RE and Lang NP (2012) Ridge preservation after tooth extraction. Clinical oral implants research 23 Suppl 6:147-56. doi: 10.1111/j.1600-0501.2012.02560.x

[7] MacBeth N, Trullenque-Eriksson A, Donos N and Mardas N (2016) Hard and soft tissue changes following alveolar ridge preservation: a systematic review. Clinical oral implants research. doi: 10.1111/clr.12911

[8] Vittorini Orgeas G, Clementini M, De Risi V and de Sanctis M (2013) Surgical techniques for alveolar socket preservation: a systematic review. The International journal of oral \& maxillofacial implants 28:1049-61. doi: $10.11607 /$ jomi.2670

[9] Iasella JM, Greenwell H, Miller RL, Hill M, Drisko C, Bohra AA and Scheetz JP (2003) Ridge preservation with freeze-dried bone allograft and a collagen membrane compared to extraction alone for implant site development: a clinical and histologic study in humans. Journal of periodontology 74:990-9. doi: 10.1902/jop.2003.74.7.990

[10] Fickl S, Schneider D, Zuhr O, Hinze M, Ender A, Jung RE and Hurzeler MB (2009) Dimensional changes of the ridge contour after socket preservation and buccal overbuilding: an animal study. Journal of clinical periodontology 36:442-8. doi: 10.1111/j.1600-051X.2009.01381.x

[11] Fickl S, Zuhr O, Wachtel H, Kebschull M and Hurzeler MB (2009) Hard tissue alterations after socket preservation with additional buccal overbuilding: a study in the beagle dog. Journal of clinical periodontology 36:898-904. doi: 10.1111/j.1600-051X.2009.01463.x

[12] Lee JS, Jung JS, Im GI, Kim BS, Cho KS and Kim CS (2015) Ridge regeneration of damaged extraction sockets using rhBMP-2: an experimental study in canine. Journal of clinical periodontology 42:678-87. doi: $10.1111 /$ jcpe. 12414

[13] Vignoletti F and Abrahamsson I (2012) Quality of reporting of experimental research in implant dentistry. Critical aspects in design, outcome assessment and model validation. Journal of clinical periodontology 39 Suppl 12:6-27. doi: 10.1111/j.1600-051X.2011.01830.x

[14] Kilkenny C, Browne WJ, Cuthill IC, Emerson M and Altman DG (2010) Improving bioscience research reporting: the ARRIVE guidelines for reporting animal research. PLoS Biol 8:e1000412. doi: 
10.1371/journal.pbio. 1000412

[15] Sanz-Sanchez I, Ortiz-Vigon A, Sanz-Martin I, Figuero E and Sanz M (2015) Effectiveness of Lateral Bone Augmentation on the Alveolar Crest Dimension: A Systematic Review and Meta-analysis. Journal of dental research 94:128S-42S. doi: 10.1177/0022034515594780

[16] Fiorellini JP, Howell TH, Cochran D, Malmquist J, Lilly LC, Spagnoli D, Toljanic J, Jones A and Nevins M (2005) Randomized study evaluating recombinant human bone morphogenetic protein-2 for extraction socket augmentation. Journal of periodontology 76:605-13. doi: 10.1902/jop.2005.76.4.605

[17] Howell TH, Fiorellini J, Jones A, Alder M, Nummikoski P, Lazaro M, Lilly L and Cochran D (1997) A feasibility study evaluating rhBMP-2/absorbable collagen sponge device for local alveolar ridge preservation or augmentation. The International journal of periodontics \& restorative dentistry 17:124-39.

[18] Kim YJ, Lee JY, Kim JE, Park JC, Shin SW and Cho KS (2014) Ridge preservation using demineralized bone matrix gel with recombinant human bone morphogenetic protein-2 after tooth extraction: a randomized controlled clinical trial. Journal of oral and maxillofacial surgery : official journal of the American Association of Oral and Maxillofacial Surgeons 72:1281-90. doi: 10.1016/j.joms.2014.01.022

[19] Thoma DS, Naenni N, Benic GI, Munoz F, Hammerle CHF and Jung RE (2017) Effect of ridge preservation for early implant placement - is there a need to remove the biomaterial? Journal of clinical periodontology 44:556-565. doi: $10.1111 /$ jcpe. 12709

[20] Jung UW, Lee JS, Lee G, Lee IK, Hwang JW, Kim MS, Choi SH and Chai JK (2013) Role of collagen membrane in lateral onlay grafting with bovine hydroxyapatite incorporated with collagen matrix in dogs. $\mathrm{J}$ Periodontal Implant Sci 43:64-71. doi: 10.5051/jpis.2013.43.2.64

[21] Perelman-Karmon M, Kozlovsky A, Liloy R and Artzi Z (2012) Socket site preservation using bovine bone mineral with and without a bioresorbable collagen membrane. The International journal of periodontics \& restorative dentistry 32:459-65.

[22] Araujo MG, Wennstrom JL and Lindhe J (2006) Modeling of the buccal and lingual bone walls of fresh extraction sites following implant installation. Clinical oral implants research 17:606-14. doi: 10.1111/j.16000501.2006.01315.x

[23] Caneva M, Botticelli D, Pantani F, Baffone GM, Rangel IG, Jr. and Lang NP (2012) Deproteinized bovine bone mineral in marginal defects at implants installed immediately into extraction sockets: an experimental study in dogs. Clinical oral implants research 23:106-12. doi: 10.1111/j.1600-0501.2011.02202.x 
[24] Delgado-Ruiz R, Romanos GE, Alexandre Gerhke S, Gomez-Moreno G, Mate-Sanchez de Val JE and Calvo-Guirado JL (2016) Biological effects of compressive forces exerted on particulate bone grafts during socket preservation: animal study. Clinical oral implants research. doi: 10.1111/clr.12942

[25] Kim JJ, Schwarz F, Song HY, Choi Y, Kang KR and Koo KT (2016) Ridge preservation of extraction sockets with chronic pathology using Bio-Oss(R) Collagen with or without collagen membrane: an experimental study in dogs. Clinical oral implants research. doi: 10.1111/clr.12870

[26] Al-Askar M, O'Neill R, Stark PC, Griffin T, Javed F and Al-Hezaimi K (2013) Effect of single and contiguous teeth extractions on alveolar bone remodeling: a study in dogs. Clinical implant dentistry and related research 15:569-75. doi: 10.1111/j.1708-8208.2011.00403.x

[27] Calvo-Guirado JL, Boquete-Castro A, Negri B, Delgado Ruiz R, Gomez-Moreno G and Iezzi G (2014) Crestal bone reactions to immediate implants placed at different levels in relation to crestal bone. A pilot study in Foxhound dogs. Clinical oral implants research 25:344-51. doi: 10.1111/clr.12110

[1] Avila-Ortiz G, Elangovan S, Kramer KW, Blanchette D and Dawson DV (2014) Effect of alveolar ridge preservation after tooth extraction: a systematic review and meta-analysis. Journal of dental research 93:950-8. doi: $10.1177 / 0022034514541127$

[2] De Risi V, Clementini M, Vittorini G, Mannocci A and De Sanctis M (2015) Alveolar ridge preservation techniques: a systematic review and meta-analysis of histological and histomorphometrical data. Clinical oral implants research 26:50-68. doi: 10.1111/clr.12288

[3] Mardas N, Trullenque-Eriksson A, MacBeth N, Petrie A and Donos N (2015) Does ridge preservation following tooth extraction improve implant treatment outcomes: a systematic review: Group 4: Therapeutic concepts \& methods. Clinical oral implants research 26 Suppl 11:180-201. doi: 10.1111/clr.12639

[4] Vignoletti F, Matesanz P, Rodrigo D, Figuero E, Martin C and Sanz M (2012) Surgical protocols for ridge preservation after tooth extraction. A systematic review. Clinical oral implants research 23 Suppl 5:22-38. doi: 10.1111/j.1600-0501.2011.02331.x

[5] Willenbacher M, Al-Nawas B, Berres M, Kammerer PW and Schiegnitz E (2015) The Effects of Alveolar Ridge Preservation: A Meta-Analysis. Clinical implant dentistry and related research. doi: 10.1111/cid.12364

[6] Wang RE and Lang NP (2012) Ridge preservation after tooth extraction. Clinical oral implants research 23 Suppl 6:147-56. doi: 10.1111/j.1600-0501.2012.02560.x

[7] MacBeth N, Trullenque-Eriksson A, Donos N and Mardas N (2016) Hard and soft tissue changes following 
alveolar ridge preservation: a systematic review. Clinical oral implants research. doi: 10.1111/clr.12911

[8] Vittorini Orgeas G, Clementini M, De Risi V and de Sanctis M (2013) Surgical techniques for alveolar socket preservation: a systematic review. The International journal of oral \& maxillofacial implants 28:1049-61. doi: $10.11607 /$ jomi.2670

[9] Iasella JM, Greenwell H, Miller RL, Hill M, Drisko C, Bohra AA and Scheetz JP (2003) Ridge preservation with freeze-dried bone allograft and a collagen membrane compared to extraction alone for implant site development: a clinical and histologic study in humans. Journal of periodontology 74:990-9. doi: 10.1902/jop.2003.74.7.990

[10] Fickl S, Schneider D, Zuhr O, Hinze M, Ender A, Jung RE and Hurzeler MB (2009) Dimensional changes of the ridge contour after socket preservation and buccal overbuilding: an animal study. Journal of clinical periodontology 36:442-8. doi: 10.1111/j.1600-051X.2009.01381.x

[11] Fickl S, Zuhr O, Wachtel H, Kebschull M and Hurzeler MB (2009) Hard tissue alterations after socket preservation with additional buccal overbuilding: a study in the beagle dog. Journal of clinical periodontology 36:898-904. doi: 10.1111/j.1600-051X.2009.01463.x

[12] Lee JS, Jung JS, Im GI, Kim BS, Cho KS and Kim CS (2015) Ridge regeneration of damaged extraction sockets using rhBMP-2: an experimental study in canine. Journal of clinical periodontology 42:678-87. doi: $10.1111 /$ jcpe. 12414

[13] Vignoletti F and Abrahamsson I (2012) Quality of reporting of experimental research in implant dentistry. Critical aspects in design, outcome assessment and model validation. Journal of clinical periodontology 39 Suppl 12:6-27. doi: 10.1111/j.1600-051X.2011.01830.x

[14] Kilkenny C, Browne WJ, Cuthill IC, Emerson M and Altman DG (2010) Improving bioscience research reporting: the ARRIVE guidelines for reporting animal research. PLoS Biol 8:e1000412. doi: 10.1371/journal.pbio. 1000412

[15] Sanz-Sanchez I, Ortiz-Vigon A, Sanz-Martin I, Figuero E and Sanz M (2015) Effectiveness of Lateral Bone Augmentation on the Alveolar Crest Dimension: A Systematic Review and Meta-analysis. Journal of dental research 94:128S-42S. doi: 10.1177/0022034515594780

[16] Fiorellini JP, Howell TH, Cochran D, Malmquist J, Lilly LC, Spagnoli D, Toljanic J, Jones A and Nevins M (2005) Randomized study evaluating recombinant human bone morphogenetic protein-2 for extraction socket augmentation. Journal of periodontology 76:605-13. doi: 10.1902/jop.2005.76.4.605 
[17] Howell TH, Fiorellini J, Jones A, Alder M, Nummikoski P, Lazaro M, Lilly L and Cochran D (1997) A feasibility study evaluating rhBMP-2/absorbable collagen sponge device for local alveolar ridge preservation or augmentation. The International journal of periodontics \& restorative dentistry 17:124-39.

[18] Kim YJ, Lee JY, Kim JE, Park JC, Shin SW and Cho KS (2014) Ridge preservation using demineralized bone matrix gel with recombinant human bone morphogenetic protein-2 after tooth extraction: a randomized controlled clinical trial. Journal of oral and maxillofacial surgery : official journal of the American Association of Oral and Maxillofacial Surgeons 72:1281-90. doi: 10.1016/j.joms.2014.01.022

[19] Thoma DS, Naenni N, Benic GI, Munoz F, Hammerle CHF and Jung RE (2017) Effect of ridge preservation for early implant placement - is there a need to remove the biomaterial? Journal of clinical periodontology 44:556-565. doi: 10.1111/jcpe.12709

[20] Jung UW, Lee JS, Lee G, Lee IK, Hwang JW, Kim MS, Choi SH and Chai JK (2013) Role of collagen membrane in lateral onlay grafting with bovine hydroxyapatite incorporated with collagen matrix in dogs. J Periodontal Implant Sci 43:64-71. doi: 10.5051/jpis.2013.43.2.64

[21] Perelman-Karmon M, Kozlovsky A, Liloy R and Artzi Z (2012) Socket site preservation using bovine bone mineral with and without a bioresorbable collagen membrane. The International journal of periodontics \& restorative dentistry 32:459-65.

[22] Araujo MG, Wennstrom JL and Lindhe J (2006) Modeling of the buccal and lingual bone walls of fresh extraction sites following implant installation. Clinical oral implants research 17:606-14. doi: 10.1111/j.16000501.2006.01315.x

[23] Caneva M, Botticelli D, Pantani F, Baffone GM, Rangel IG, Jr. and Lang NP (2012) Deproteinized bovine bone mineral in marginal defects at implants installed immediately into extraction sockets: an experimental study in dogs. Clinical oral implants research 23:106-12. doi: 10.1111/j.1600-0501.2011.02202.x

[24] Delgado-Ruiz R, Romanos GE, Alexandre Gerhke S, Gomez-Moreno G, Mate-Sanchez de Val JE and Calvo-Guirado JL (2016) Biological effects of compressive forces exerted on particulate bone grafts during socket preservation: animal study. Clinical oral implants research. doi: 10.1111/clr.12942

[25] Kim JJ, Schwarz F, Song HY, Choi Y, Kang KR and Koo KT (2016) Ridge preservation of extraction sockets with chronic pathology using Bio-Oss(R) Collagen with or without collagen membrane: an experimental study in dogs. Clinical oral implants research. doi: 10.1111/clr.12870

[26] Al-Askar M, O'Neill R, Stark PC, Griffin T, Javed F and Al-Hezaimi K (2013) Effect of single and 
contiguous teeth extractions on alveolar bone remodeling: a study in dogs. Clinical implant dentistry and related research 15:569-75. doi: 10.1111/j.1708-8208.2011.00403.x

[27] Calvo-Guirado JL, Boquete-Castro A, Negri B, Delgado Ruiz R, Gomez-Moreno G and Iezzi G (2014) Crestal bone reactions to immediate implants placed at different levels in relation to crestal bone. A pilot study in Foxhound dogs. Clinical oral implants research 25:344-51. doi: 10.1111/clr.12110

1. Avila-Ortiz G, Elangovan S, Kramer KW, Blanchette D, Dawson DV (2014) Effect of alveolar ridge preservation after tooth extraction: a systematic review and meta-analysis. Journal of dental research 93 (10):950-958. doi:10.1177/0022034514541127

2. De Risi V, Clementini M, Vittorini G, Mannocci A, De Sanctis M (2015) Alveolar ridge preservation techniques: a systematic review and meta-analysis of histological and histomorphometrical data. Clinical oral implants research 26 (1):50-68. doi:10.1111/clr.12288

3. Mardas N, Trullenque-Eriksson A, MacBeth N, Petrie A, Donos N (2015) Does ridge preservation following tooth extraction improve implant treatment outcomes: a systematic review: Group 4: Therapeutic concepts \& methods. Clinical oral implants research 26 Suppl 11:180-201. doi:10.1111/clr.12639

4. Vignoletti F, Matesanz P, Rodrigo D, Figuero E, Martin C, Sanz M (2012) Surgical protocols for ridge preservation after tooth extraction. A systematic review. Clinical oral implants research 23 Suppl 5:22-38. doi:10.1111/j.1600-0501.2011.02331.x

5. Willenbacher M, Al-Nawas B, Berres M, Kammerer PW, Schiegnitz E (2015) The Effects of Alveolar Ridge Preservation: A Meta-Analysis. Clinical implant dentistry and related research. doi:10.1111/cid.12364

6. Wang RE, Lang NP (2012) Ridge preservation after tooth extraction. Clinical oral implants research 23 Suppl 6:147-156. doi:10.1111/j.1600-0501.2012.02560.x

7. MacBeth N, Trullenque-Eriksson A, Donos N, Mardas N (2016) Hard and soft tissue changes following alveolar ridge preservation: a systematic review. Clinical oral implants research. doi:10.1111/clr.12911

8. Vittorini Orgeas G, Clementini M, De Risi V, de Sanctis M (2013) Surgical techniques for alveolar socket preservation: a systematic review. The International journal of oral \& maxillofacial implants 28 (4):1049-1061. doi:10.11607/jomi.2670

9. Iasella JM, Greenwell H, Miller RL, Hill M, Drisko C, Bohra AA, Scheetz JP (2003) Ridge preservation with freeze-dried bone allograft and a collagen membrane compared to extraction alone for implant site development: a clinical and histologic study in humans. Journal of periodontology 74 (7):990-999. 
doi:10.1902/jop.2003.74.7.990

10. Fickl S, Schneider D, Zuhr O, Hinze M, Ender A, Jung RE, Hurzeler MB (2009) Dimensional changes of the ridge contour after socket preservation and buccal overbuilding: an animal study. Journal of clinical periodontology 36 (5):442-448. doi:10.1111/j.1600-051X.2009.01381.x

11. Fickl S, Zuhr O, Wachtel H, Kebschull M, Hurzeler MB (2009) Hard tissue alterations after socket preservation with additional buccal overbuilding: a study in the beagle dog. Journal of clinical periodontology 36 (10):898-904. doi:10.1111/j.1600-051X.2009.01463.x

12. Lee JS, Jung JS, Im GI, Kim BS, Cho KS, Kim CS (2015) Ridge regeneration of damaged extraction sockets using rhBMP-2: an experimental study in canine. Journal of clinical periodontology 42 (7):678-687. doi:10.1111/jepe. 12414

13. Vignoletti F, Abrahamsson I (2012) Quality of reporting of experimental research in implant dentistry. Critical aspects in design, outcome assessment and model validation. Journal of clinical periodontology 39 Suppl 12:6-27. doi:10.1111/j.1600-051X.2011.01830.x

14. Kilkenny C, Browne WJ, Cuthill IC, Emerson M, Altman DG (2010) Improving bioscience research reporting: the ARRIVE guidelines for reporting animal research. PLoS Biol 8 (6):e1000412. doi:10.1371/journal.pbio.1000412

15. Sanz-Sanchez I, Ortiz-Vigon A, Sanz-Martin I, Figuero E, Sanz M (2015) Effectiveness of Lateral Bone Augmentation on the Alveolar Crest Dimension: A Systematic Review and Meta-analysis. Journal of dental research 94 (9 Suppl):128S-142S. doi:10.1177/0022034515594780

16. Fiorellini JP, Howell TH, Cochran D, Malmquist J, Lilly LC, Spagnoli D, Toljanic J, Jones A, Nevins M (2005) Randomized study evaluating recombinant human bone morphogenetic protein-2 for extraction socket augmentation. Journal of periodontology 76 (4):605-613. doi:10.1902/jop.2005.76.4.605

17. Howell TH, Fiorellini J, Jones A, Alder M, Nummikoski P, Lazaro M, Lilly L, Cochran D (1997) A feasibility study evaluating rhBMP-2/absorbable collagen sponge device for local alveolar ridge preservation or augmentation. The International journal of periodontics \& restorative dentistry 17 (2):124-139

18. Kim YJ, Lee JY, Kim JE, Park JC, Shin SW, Cho KS (2014) Ridge preservation using demineralized bone matrix gel with recombinant human bone morphogenetic protein-2 after tooth extraction: a randomized controlled clinical trial. Journal of oral and maxillofacial surgery : official journal of the American Association of Oral and Maxillofacial Surgeons 72 (7):1281-1290. doi:10.1016/j.joms.2014.01.022 
19. Thoma DS, Naenni N, Benic GI, Munoz F, Hammerle CHF, Jung RE (2017) Effect of ridge preservation for early implant placement - is there a need to remove the biomaterial? Journal of clinical periodontology 44 (5):556-565. doi:10.1111/jcpe. 12709

20. Jung UW, Lee JS, Lee G, Lee IK, Hwang JW, Kim MS, Choi SH, Chai JK (2013) Role of collagen membrane in lateral onlay grafting with bovine hydroxyapatite incorporated with collagen matrix in dogs. J Periodontal Implant Sci 43 (2):64-71. doi:10.5051/jpis.2013.43.2.64

21. Perelman-Karmon M, Kozlovsky A, Liloy R, Artzi Z (2012) Socket site preservation using bovine bone mineral with and without a bioresorbable collagen membrane. The International journal of periodontics \& restorative dentistry $32(4): 459-465$

22. Araujo MG, Wennstrom JL, Lindhe J (2006) Modeling of the buccal and lingual bone walls of fresh extraction sites following implant installation. Clinical oral implants research 17 (6):606-614. doi:10.1111/j.1600-0501.2006.01315.x

23. Caneva M, Botticelli D, Pantani F, Baffone GM, Rangel IG, Jr., Lang NP (2012) Deproteinized bovine bone mineral in marginal defects at implants installed immediately into extraction sockets: an experimental study in dogs. Clinical oral implants research 23 (1):106-112. doi:10.1111/j.1600-0501.2011.02202.x

24. Delgado-Ruiz R, Romanos GE, Alexandre Gerhke S, Gomez-Moreno G, Mate-Sanchez de Val JE, CalvoGuirado JL (2016) Biological effects of compressive forces exerted on particulate bone grafts during socket preservation: animal study. Clinical oral implants research. doi:10.1111/clr.12942

25. Kim JJ, Schwarz F, Song HY, Choi Y, Kang KR, Koo KT (2016) Ridge preservation of extraction sockets with chronic pathology using Bio-Oss(R) Collagen with or without collagen membrane: an experimental study in dogs. Clinical oral implants research. doi:10.1111/clr.12870

26. Al-Askar M, O'Neill R, Stark PC, Griffin T, Javed F, Al-Hezaimi K (2013) Effect of single and contiguous teeth extractions on alveolar bone remodeling: a study in dogs. Clinical implant dentistry and related research 15 (4):569-575. doi:10.1111/j.1708-8208.2011.00403.x

27. Calvo-Guirado JL, Boquete-Castro A, Negri B, Delgado Ruiz R, Gomez-Moreno G, Iezzi G (2014) Crestal bone reactions to immediate implants placed at different levels in relation to crestal bone. A pilot study in Foxhound dogs. Clinical oral implants research 25 (3):344-351. doi:10.1111/clr.12110 


\section{Figure legends}

Figure 1. Clinical photographs of the surgical procedure: (A) labial overaugmentation was performed. (B) the socket was filled with putty type porcine bone substitute. (C) primary flap closure was achieved.

Figure 2. Histomorphometric measurements of the alveolus. The socket was divided into three parts: coronal, middle, and apical 1/3. The areas of new bone, residual PB, and nonmineralized tissue were measured within those three parts and the overaugmented area. The horizontal width from the inner surface of the lingual wall to the outermost surface of the augmented area or labial wall was measured at 1,3 , and $5 \mathrm{~mm}$ below the lingual crest.

Figure 3. Representative microcomputed tomographic images. (A) BMP group. (B) control group. Red coded area: augmented volume.

Figure 4. Histologic observations in the BMP group (Masson's trichrome stain). (A) Overall view of the alveolus. High-magnification images of the boxed areas in the overaugmented area (B), coronal 1/3 (C), middle 1/3 (D), and apical 1/3 (E). *: newly formed bone, yellow asterisk: residual porcine bone substitute

Figure 5. Histologic observations in the control group (Masson's trichrome stain). (A) Overall view of the alveolus. High-magnification images of the boxed areas in the overaugmented area (B), coronal 1/3 (C), middle 1/3 (D), and apical 1/3 (E). *: newly formed bone, yellow asterisk: residual porcine bone substitute

Figure 6. Percentages of tissue components in the apical, middle, and coronal $1 / 3$ within the socket, and in the overaugmented area. (A) control group, (B) BMP group. 